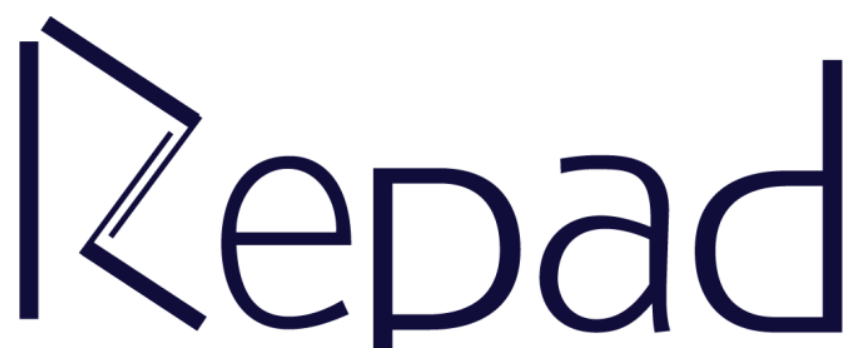

Vol. 2, n. 3, Dezembro/2018

Revista Estudos e

Pesquisas em Administração

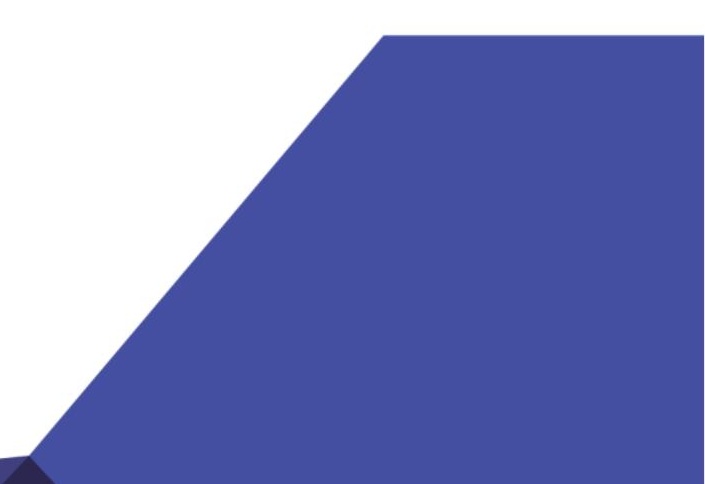




\title{
ANÁLISE DA APLICABILIDADE DA FERRAMENTA CANVAS COMO ESTÍMULO DO EMPREENDEDORISMO AOS ACADÊMICOS NA UNEMAT - CAMPUS DIAMANTINO
}

\author{
Maiza Maria Lachman \\ Universidade do Estado de Mato Grosso \\ https://orcid.org/0000-0002-1004-2859 \\ Walmilso Castorino de Campos \\ Universidade do Estado de Mato Grosso \\ https://orcid.org/0000-0003-1711-3362
}

\section{RESUMO}

Empreender não significa abrir uma empresa física. Empreendedorismo está ligado às ações do indivíduo, é ser empreendedor. É possuir características empreendedoras e mostrar para o mundo ideias inovadoras, que normalmente vão contra ao que já está estabelecido como algo fora do comum. Competições, jornadas, eventos, palestras, tudo isso é válido e está sendo usado como ferramenta para instigar o empreendedorismo nas pessoas, por instituições ou por grandes empreendedores de sucesso. Esta pesquisa foi desenvolvida a partir do momento em que se percebeu que os acadêmicos do curso de administração da Universidade do Estado de Mato Grosso Campus de Diamantino, pouco conheciam sobre ferramentas que estão sendo bastante utilizadas no mundo dos negócios atualmente. E então foi organizado um evento, "Jornada Empreendedora de Administração" para instigar o empreendedorismo aos acadêmicos através de atividades interativas e aplicabilidade da ferramenta Canvas, criada por Osterwalder em 2004, para desenvolver modelos de negócios inovadores. O evento foi desenhado com adaptações para a realidade do campus e realizado durante quatro noites. Os resultados foram que os acadêmicos conseguiram desenvolver negócios com diferenciais, e que o evento contribuiu tanto com o profissional quanto com o pessoal dos participantes.

Palavras-chave: Empreendedorismo; Canvas; Universidade.

\section{ANALYSIS OF THE APPLICABILITY OF THE CANVAS TOOL TO ENCOURAGE ENTREPRENEURSHIP TO THE STUDENTS OF UNEMAT - DIAMANTINO CAMPUS}

\begin{abstract}
Entrepreneurship does not mean opening a physical company. Entrepreneurship is linked to the actions of the individual, is being an entrepreneur. It is about having entrepreneurial characteristics and showing to the world innovative ideas, that usually go against what is established as something unusual. Competitions, conferences, events, lectures, all this is valid and has been used as a tool to inspire entrepreneurship to people by institutions or by successful entrepreneurs. This research was developed from the realization that Administration students of the State University of Mato Grosso, Diamantino campus, knew little about tools that are frequently used in the business world nowadays. Thus, an event was organized,
\end{abstract}


"Entrepreneurial Journey", to inspire entrepreneurship to scholars through interactive activities and applicability of the Canvas tool, created by Osterwalder in 2004, to develop innovative business models. The event was designed with adaptations to the reality of the campus and lasted four evenings. The results were that the students could develop business with differentials. And through research of evaluation of the event, it was possible to notice that the Canvas tool has contributed to participants both professionally and the personally.

Keywords: Entrepreneurship; Canvas; University.

\section{INTRODUÇÃO}

De acordo com a pesquisa "Empreendedorismo nas Universidades Brasileiras - 2016", realizada pelo Serviço Brasileiro de Apoio às Micro e Pequenas Empresas (SEBRAE) em parceria com a ENDEAVOR Brasil, as universidades ainda encontram muitas dificuldades em apoiar os acadêmicos em iniciativas empreendedoras.

Sendo suas principais dificuldades: a) $\mathrm{O}$ fato de que, de modo geral, as universidades não possuem estrutura que apoie a jornada completa do empreendedor. b) A universidade está de certa forma desconectada do mercado. c) A ação atual da universidade não estimula a inovação e o sonho grande nos acadêmicos. (SEBRAE NACIONAL, 2017). Quer dizer, as universidades não demonstram ser ativas diante da nova exigência do mercado. Exceto pelos esforços de alguns professores engajados com o tema e comprometidos com o desenvolvimento dos acadêmicos.

Em relação aos acadêmicos, esta mesma pesquisa revelou que, aqueles que cursam disciplinas de empreendedorismo também pretendem empreender nos próximos três anos, porém, tendem a demorar mais para abrir um negócio do que aqueles que não estão vinculados à universidade. Considera-se então, que os acadêmicos valorizam iniciativas empreendedoras da universidade, porém se preocupam mais com os possíveis desafios que encontrarão ao empreender. E com isso, o agir em prol do desenvolvimento da ideia de negócio vai sendo adiada.

O interesse por essa pesquisa surgiu a partir de uma experiência vivida pela autora no meio empreendedor. Sabe-se que existe hoje um grande estímulo no país e no mundo ao empreendedorismo e inovação através de eventos, criação de conteúdo, entre outros meios. E o SEBRAE se atenta a essa tendência produzindo conteúdo e disseminando o empreendedorismo e a inovação através de diversos canais. Sendo um deles o Desafio Universitário Empreendedor - Sebrae (DUE).

A autora teve seu primeiro contato com a ferramenta Canvas, através da participação desse evento, no qual se sentiu estimulada a contribuir com a disseminação do empreendedorismo no meio acadêmico através da aplicabilidade de tal ferramenta, e a incentivar os acadêmicos a tirarem suas ideias do papel.

Essa pesquisa tem a intenção de mostrar que é possível agir em prol do desenvolvimento das ideias de forma simples, visualizando e interligando todos os aspectos necessários para a construção do negócio, e estimulando o comportamento empreendedor. Sua importância está em disseminar a ideia de que todos podem ser empreendedores. Que de acordo com Chiavenato (2012), empreendedores são pessoas que assumem riscos calculados e buscam inovar constantemente, seja este dono de uma empresa, ou não.

E assim, como parte dos acadêmicos desconhece o conceito de que ser empreendedor não é o que você faz, mas sim como você age, boa parte da comunidade externa a universidade 
também desconhece. Portanto, essa pesquisa contribuiu para a disseminação da ferramenta Canvas tanto na sociedade, quanto na comunidade acadêmica. Para a sociedade externa à universidade, a pesquisa traz projetos de empreendimentos inovadores que contribuam com melhorias e desenvolvimento econômico e social para a região. E para a sociedade acadêmica, o impacto cultural proposto tende a ser significativo, não somente no campus objeto de estudo, (Unemat - campus Diamantino), mas também em toda a universidade onde servirá como piloto para iniciativas empreendedoras.

Mas como instigar o empreendedorismo aos acadêmicos na Universidade do Estado de Mato Grosso - campus Diamantino, incentivando o desenvolvimento de negócios inovadores? Teve-se como hipótese, que a demonstração da aplicabilidade da ferramenta Canvas aos acadêmicos faria com que se sentissem capazes e motivados a empreender, os incentivando, através da ferramenta, a desenvolver negócios inovadores. O incentivo ao trabalho em equipe poderia permitir com que os acadêmicos aprendessem a observar as situações ou objetos em questão sob diversas perspectivas. Instigar as características empreendedoras faria com que os acadêmicos se identifiquem também como intraempreendedores. E incentivar a criatividade, a ação e encorajar as ideias "fora da caixa" contribuiriam com a motivação dos indivíduos na buscar por inovação em diversas áreas e momentos de suas vidas.

O objetivo desta pesquisa, que consistiu em analisar a aplicabilidade da ferramenta Canvas como estímulo do empreendedorismo aos acadêmicos, foi alcançado através do estudo bibliográfico dos termos pertinentes ao tema proposto, oferta de atividades interativas propostas em forma de evento, aplicabilidade da ferramenta Canvas junto aos acadêmicos, observando o desenvolvimento da percepção dos mesmos em relação ao tema: empreendedorismo e criação de negócios inovadores. E por fim, identificar a influência da ferramenta Canvas no desenvolvimento de características empreendedoras aos acadêmicos.

\section{REFERENCIAL TEÓRICO}

\section{EMPREENDEDORISMO}

O fato de o termo empreendedorismo estar em ascensão é sustentado por Tonelli, Brito e Zambalde (2011 apud COSTA, 2012), onde o empreendedorismo é considerado o responsável pelo crescimento econômico e pela geração de emprego na atualidade. Como apresenta Costa (2012), o empreendedorismo é uma oportunidade ideal para que os indivíduos e organizações inovem e melhorem seus modelos de negócios.

Dornelas $(2008$, p. 6) argumenta o empreendedorismo como oportunidade, dizendo que, são os empreendedores que estão quebrando barreiras culturais e comerciais, criando novas relações de trabalho, novos empregos, renovando conceitos econômicos e "gerando riqueza para a sociedade". O empreendedorismo apresentado por Cardozo (2003 apud MIGLIOLI, 2006), caracteriza-se pelo enfrentar de crises com inovações. Onde, a criatividade usada para resolver problemas ganha ênfase. Mas não é desde sempre que o empreendedorismo tem destaque, pois de acordo com Dornelas (2008) não se falava sobre empreendedorismo no Brasil antes de 1990.

O movimento empreendedor brasileiro começou a ganhar forma na década de 90 , quando surgiram entidades que deram força e impulsionaram práticas empreendedoras no país. Até então, o empreendedor não tinha auxílio, nem mesmo com informações sobre como empreender. E foi com o surgimento de algumas instituições como o Sebrae, em 1972, e a 
Associação para Promoção da Excelência do Software Brasileiro (Softex), em 1996, juntamente com incubadoras de empresas e programas dentro das universidades, atores importantíssimos para o desenvolvimento do empreendedorismo no Brasil, que o empreendedorismo começou a ser discutido no Brasil (DORNELAS, 2008).

Até então, o empreendedorismo era desconhecido e sofria descrença sobre sua validade em empresas. Mas menciona Dornelas (2008), que passados 20 anos, o Brasil, com o desenvolvimento dos programas citados e muitos outros que foram realizados pelas universidades, se tornou uma das referências no mundo do empreendedorismo. Esta é a era do empreendedorismo, afirma Dornelas (2001). O mundo tem passado por várias mudanças, mesmo que pequenas e quase imperceptíveis, que estão transformando o estilo de vida das pessoas aos poucos. E por trás dessas mudanças estão os empreendedores que dão asas a ideias inovadoras, com suas características únicas e capazes de mover o mundo, por simplesmente serem apaixonados pelo que fazem e pelo desejo de mudar e melhorar a forma como as coisas acontecem.

Dornelas (2001) questiona o porquê de o empreendedorismo estar tão intenso nos dias de hoje e por que não o estava antes. $\mathrm{O}$ mesmo responde que o desenvolvimento dessa era empreendedora se deu por conta do próprio avanço tecnológico. $\mathrm{O}$ avanço do mundo exigiu que as pessoas abrissem a mente e pensassem em alternativas para conseguir acompanha-lo. $\mathrm{O}$ questionamento de Dornelas vai de encontro com o conceito de Dolabela (1999, p. 28) sobre o que é ser empreendedor, onde ele diz que "empreendedor é um ser social, produto do meio em que vive (época e lugar) [...]”".

Com isso Dornelas (2001) deixa muito claro que o empreendedorismo não é um modismo e sim uma consequência dos rápidos avanços tecnológicos, sociais e culturais do mundo. O mundo muda e o empreendedor se desperta. $\mathrm{O}$ termo empreendedorismo é a tradução da palavra francesa entrepreneurship, e empreendedor é a tradução do termo francês entrepreneur, que segundo Chiavenato $(2012$, p. 3) significa "aquele que assume riscos e começa algo inteiramente novo", e foi usado pela primeira vez em 1725.

Portanto, "o empreendedorismo se refere a assumir riscos", conforme indicado por Knight (1967) e Druker (1970) ambos apresentados por Chiavenato (2012, p. 8), uma vez que o empreendedor aparece com novas ideias, novos pensamentos e enfrenta o pensamento já estabelecido das pessoas correndo o risco de não aceitação. Percebe-se que é quase impossível falar do empreendedorismo sem mencionar o empreendedor, ou vice e versa.

Muitas foram as pesquisas que tentaram definir o empreendedor, principal agente do empreendedorismo. Mas de acordo com Costa (2012), por mais que essas definições sejam distintas e diversas, existem, no geral, duas abordagens a respeito dessa definição. A abordagem behaviorista ou comportamental, e a abordagem econômica. Na abordagem econômica, de acordo com Costa (2012), o empreendedor é o "empresário", que possui empresa, emprega pessoas e contribui para a economia financeiramente. É aquele que tem ideias inovadoras, calcula os riscos dessa ideia e a desenvolve, transformando-a em um negócio rentável.

E ainda de acordo com Costa (2012), a abordagem comportamental, define o empreendedor como aquele que possui um comportamento e um conjunto de características diferentes dos demais na sociedade. Esta abordagem ainda considera aspectos sociais e as influências que o indivíduo sofre no meio em que nasceu, cresceu e convive. A exemplo dessa abordagem comportamental tem-se o conceito de alguns autores sobre o ser empreendedor.

Como Dornelas (2001), que acredita que a visão do autor Joseph Schumpeter (1949 apud DORNELAS, 2001) sobre o que é empreendedorismo seja a mais completa, mesmo que ainda uma das mais antigas, onde o mesmo diz que o empreendedor é aquele que quebra paradigmas e destrói o oceano vermelho já existente na economia e cria um novo oceano azul 
introduzindo no mercado produtos e serviços que antes não existiam. Esse pensamento de Schumpeter (1949 apud DORNELAS, 2001) condiz com o que Dolabela (1999, p. 28) conceitua sobre o ser empreendedor: "o empreendedor é um agente de mudanças".

De acordo com Castanhar (2007 apud COSTA, 2012) por mais que existam diferentes conceitos sobre o que é ser empreendedor, nesta abordagem behaviorista ou comportamental, existem algumas características que aparecem na maioria dessas definições. Características como: valores e cultura empreendedora aprendida através de meio em que vive, durante a juventude; apresentar ter experiência em negócios; ser diferente; saber seguir a intuição; ser fortemente e incansavelmente envolvido com o trabalho; ser capaz de assumir riscos calculados; ser sonhador, no sentido de sonhar grande, mas com os "pés no chão"; é líder, e possui um jeito diferente de liderar; e desenvolve seu próprio processo de aprendizado.

Porém, o empreendedor, de acordo com Chiavenato (2012), não é somente aquele que possui uma empresa, ele é muito mais que isso, ele é o que promove mudanças, possui ideias mais dinâmicas e que se reinventa continuamente. Portanto, considera-se também empreendedoras todas as pessoas que se preocupam em buscar inovação no que fazem e assumem os riscos necessários, mesmo que trabalhando para outras pessoas ou em serviços voluntários.

Costa (2012) mesmo afirma que a abordagem econômica é uma abordagem antiga, e que hoje, de certa forma, se mescla com a abordagem comportamental. Onde o empreendedor é aquele que provoca mudanças no ambiente em que se encontra. Através de suas atitudes, características e habilidades, o empreendedor desafia o status quo e promove certo desequilíbrio nos processos existentes, seja por meio uma sugestão de uma simples mudança na produção de um produto, ou na abertura de um novo mercado. Em tudo ele estará provocando uma mudança na economia, em direção ao desenvolvimento da mesma (COSTA, 2012).

\section{INTRAEMPREENDEDORISMO}

De acordo com Sequeira (2005 apud HENRIQUE, 2008, p. 115) foi instalado "um ambiente de hipercompetição" no mundo dos negócios, onde as empresas se veem obrigadas a adotar uma nova forma de gestão, "com predomínio no desenvolvimento da capacidade de inovação de seus indivíduos, ou seja, por meio de ações intraempreendedores e/ou de empreendedorismo corporativo". Para Davis (1991 apud SALVI, 2010), esse novo cenário empreendedor muda a relação entre trabalhadores e as empresas, onde, cada colaborador é um empresário.

Isso ressalta o quanto a personificação dos clientes e os profissionais empreendedores estão sendo valorizados. Por mais que os dizeres de Davis (1991 apud SALVI, 2010) tenham já alguns anos, percebe-se que esse cenário está ainda mais aquecido na atualidade. Aumenta a cada dia mais, de acordo com Salvi (2010), os esforços das organizações para o estímulo dos indivíduos à inovação, à visão holística, ao trabalho em equipe e à autonomia profissional para estabelecer e controlar suas próprias atividades, com o intuito de estimular a pró-atividade e criatividade nos mesmos.

Como afirma Silva (2017, p. 46) "é de suma para as organizações, pois é composta por um conjunto de fatores que fazem com que a mesma possa se promover e assim tornando-se indispensável".

Assim, Zampier (2011) destaca que o intraempreendedorismo também se refere às atividades e orientações inovadoras de uma organização, ou seja, acaba sendo também parte do processo interno das empresas. Entende-se então, que o intraempreendedorismo acontece de 
maneira mais expressiva quando a organização estimula o empreendedorismo aos colaboradores.

Seguindo essa mesma linha de pensamento, Hashimoto (2006 apud ZAMPIER, 2011) reforça que o intraempreendedorismo só acontece quando há empreendedores dentro das organizações. Com isso, é compreendido que, antes de tudo a organização deve selecionar, para seu quadro de colaboradores, empreendedores. Zampier (2011) traz que podem ocorrer esforços informais, que são ações empreendedoras resultantes da criatividade individual, estimulada ou não pela organização, ou da busca pelos interesses pessoais.

Pinchot III (1989 apud ZAMPIER, 2011) define o intraempreendedor como aquele que é persistente, que possui autoconfiança, e que trabalha arduamente para alcançar seus objetivos e não por status ou dinheiro. Assim, após um estudo sobre o conceito de intraempreendedorismo, Zampier (2011), acredita que, o intraempreendedor é aquele que sonha e realiza dentro da organização assumindo as responsabilidades necessárias.

Em sua pesquisa, Filion (2004) constatou que empreendedores e intraempreendedores possuem características semelhantes, sendo as principais delas, a visão, ou concepção da ideia, e a transformação dessa ideia em realidade. Filion (2004) complementa seu pensamento, dizendo que, para que o intraempreendedor consiga fazer algo diferente, ele precisa primeiro fazer uma autoanálise, se questionando se a inovação que visualiza é o que ele realmente deseja realizar, e posteriormente identifica a melhor forma de fazê-lo. O que torna difícil imaginar uma ação inovadora concretizada sem que o autor da ação tenha primeiro realizado uma interiorização da ideia.

Algumas organizações, utilizam a prática de "job rotation" com os colaboradores para estimular o intraempreendedorismo e consequentemente o desenvolvimento de ideias inovadoras. E Filion (2004) ainda diz que as organizações que desejam contratar intraempreendedores precisam estar preparadas para vê-los fazendo coisas, mesmo que simples, de um jeito diferente. Para Filion (2004, p. 65) "o intraempreendedor é definido como uma pessoa que desempenha um papel empreendedor dentro de uma organização.".

As empresas acabam se interessando em buscar e estimular colaboradores com perfil intraempreendedor, de acordo com Filion (2004), porque geralmente os projetos criados e realizados por estes colaboradores visão redução de custos, otimização dos recursos, reativar departamentos que já não são satisfatórios o bastante e até mesmo sugerir um produto inovador para a organização.

Diferenciar-se do comum e a necessidade de realização são suas habilidades mais notáveis. Tal necessidade de realização é uma característica essencial do empreendedor, (MCCLELLAND, 1961 apud NASSIF, 2011). O jeito de pensar, a maneira de agir ou o comportamento social de pessoas empreendedoras são impulsionados por essa necessidade ou vontade de fazer as coisas acontecerem, mudar ou melhorar processos já existentes. São verdadeiros inconformados.

Shumpeter (1949 apud DORNELAS, 2001), concorda que o empreendedor é também aquele que inova dentro de negócios já existentes. Que não necessariamente crie algo totalmente novo ou do zero, mas é aquele que sabe aproveitar oportunidades, independentemente do local onde esteja. Percebe-se que o ato de empreender está bastante relacionado ao comportamento pessoal. Assim como afirma Pinchot III, (1989 apud ZAMPIER, 2011), que o Intraempreendedorismo "é um estado de espírito". Portanto, para entender o ser empreendedor faz-se necessária revisão das características empreendedoras. 


\section{CARACTERÍSTICAS DO EMPREENDEDOR}

"Gênio é $1 \%$ inspiração e $99 \%$ transpiração" Thomas Edison

Dolabela (1999) apresenta diversas características do empreendedor em sua obra, "O Segredo de Luísa". E as que chamam mais atenção são as seguintes:

- Tem iniciativa, autonomia, autoconfiança, otimismo, necessidade de realização.

- Trabalha sozinho.

- Tem perseverança [...].

- O fracasso é considerado um resultado como outro qualquer. O empreendedor aprende com os resultados negativos, com os próprios erros.

- Tem grande energia. É um trabalhador incansável. Ele é capaz de se dedicar intensamente ao trabalho e sabe concentrar seus esforços para alcançar resultados.

- Sabe fixar metas e alcança-las. Luta contra padrões impostos. Diferencia-se. Tem capacidade de ocupar um espaço não ocupado pelos outros no mercado, descobrir nichos.

- Tem sempre alto comprometimento. Crê no que faz.

- É líder. [...].

- Tece "rede de relações" [...].

- Define o que deve aprender [...].

Além dessas características, Dolabela (1999) diz que o empreendedor geralmente tem uma pessoa que o influencia ou que lhe serve de modelo ou inspiração, podendo ser essa pessoa alguém da família ou um empreendedor conhecido. De acordo com Dornelas (2001), fazem parte das características do empreendedor, a iniciativa para criar negócios do zero; o brilho nos olhos e paixão pelo que faz; criatividade na utilização dos recursos disponíveis; e aceitação da possibilidade de fracassar assumindo riscos calculados.

Para Chiavenato (2012) o empreendedor tem certo instinto para conseguir visualizar as oportunidades, criar e desenvolver negócios. E juntando essa sensibilidade com quase infinita energia do empreendedor, ele consegue tornar real suas ideias e beneficiar não só ele mesmo, mas também a sociedade a sua volta. E além dessas características o empreendedor também é líder, pois consegue trazer as pessoas para o seu lado e conduzi-las ao sucesso do negócio, motivando-as, mesmo que só pelo exemplo ou com palavras encorajadoras.

Percebe-se que a maioria das características empreendedoras apontadas por Dolabela (1999) são bastante parecidas com o pensamento de Chiavenato (2012) e Dornelas (2001). Porém, uma dessas características entra em convergência com as demais, que é a de que o empreendedor trabalha sozinho. De acordo com os autores, acredita-se que o empreendedor tem também característica de líder e de trabalho em equipe. Mas quando Dolabela (1999) diz que o empreendedor trabalha sozinho, o mesmo se refere ao fato de que o empreendedor é bastante intraempreendedor, e que por vezes corre atrás das coisas sozinho sim.

Pois por mais que ele consiga conquistar as pessoas, só ele vai conseguir fazer as coisas fluírem no negócio, não por não saber disseminar a sua ideia, mas porque ela nasceu dentro dele e nenhum outro vai conseguir pensar e agir como ele. Já Maximiano (2012), traz que essa ideia de que o empreendedor é alguém que gosta de trabalhar sozinho, diz respeito ao fato de que o empreendedor tem plena consciência de que a responsabilidade de fazer o negócio 
funcionar e acontecer é somente dele. E por conta disso, o mesmo, não transfere tamanha responsabilidade para outros.

"Mas o que exatamente faz de alguém um empreendedor?". Este foi o questionamento de Maximiano (2012, p. 4) para compreensão do perfil empreendedor, onde o mesmo encontrou algumas características que se destacam nos estudos sobre os traços dessa personalidade empreendedora. São elas: a criatividade; a capacidade de implementar ideias; disposição para assumir riscos; perseverança e otimismo; e senso de independência. Maximiano (2012) complementa seu pensamento dizendo que, em relação às características, criatividade e capacidade de realizar ou implementar as ideias, estas são características que se complementam e que são traços fundamentais da personalidade do empreendedor.

Pois de nada adiantaria ter muitas ideias se nenhuma delas se concretizasse. E então o indivíduo não seria de fato empreendedor de acordo com os demais autores citados acima, onde enfatizam que o empreendedor surge da necessidade intrínseca de realizações. Conclui Maximiano (2012, p. 5) que, "na verdade a receita do sucesso é a soma de boas doses de inspiração e transpiração".

Vale ressaltar também, que de acordo do Maximiano (2012), as características de perseverança e otimismo, são uma tradução do compromisso que o empreendedor possui com seu negócio. O empreendedor possui uma crença muito forte de sucesso e não desiste com facilidade do seu negócio, nem desanima mediante os obstáculos que surgem em sua jornada empreendedora.

\section{O ENSINO DO EMPREENDEDORISMO}

Completamente diferente dos objetivos atuais, o ensino do empreendedorismo, segundo Henrique (2008), surgiu logo após a Segunda Guerra Mundial, quando o contexto daquele período exigiu que os ex-combatentes da guerra fossem preparados para entrar no mercado de trabalho. Pois com certeza não seriam simplesmente admitidos por saberem manusear armas de fogo, ou seja, precisavam ter um diferencial. Ou, precisavam ter o conhecimento necessário para desenvolver o próprio negócio.

O ensino do empreendedorismo teve início nos Estados Unidos com Myles Mace lecionando o primeiro curso de empreendedorismo em 1947 na Escola de Administração de Harvard (KATZ, 2003 apud HENRIQUE, 2008). Porém, a expansão definitiva do ensino do empreendedorismo, de acordo com Henrique (2008) aconteceu na década de 80, por conta da necessidade de desenvolvimento da gestão das empresas.

Com os resultados positivos que o ensino do empreendedorismo trazia, tanto para os acadêmicos quanto para o crescimento das organizações, houve um aumento muito grande da adoção de disciplinas empreendedoras pelas Instituições de Ensino Superior (IES), tanto que passaram "de pouco mais de 50 em 1975 para mais de mil em 1988" (DOLABELA 1999 apud HENRIQUE, 2008).

No Brasil, o ensino do empreendedorismo, e da administração, foi um pouco mais tardia em relação aos países desenvolvidos. De acordo com Henrique (2008), isso ocorreu justamente por conta do contexto econômico industrial em que o país se encontrava. Onde, a industrialização apresentou um crescimento significativo somente a partir de da década de 50 . No entanto, de acordo com Henrique (2008), o ensino do empreendedorismo no país está ganhando força.

Por mais que, não exista um padrão para ensinar o empreendedorismo ou fórmula mágica para fazer com que os acadêmicos desenvolvam o perfil empreendedor, Souza (2005, 
apud, HENRIQUE, 2008), diz que o desenvolvimento da habilidade empreendedora envolve bem mais que o aprendizado de conhecimentos técnicos, envolvendo também a maneira de pensar e agir. E não só na Administração, mas também em outros cursos o ensino do empreendedorismo é válido. Pois entende-se que o empreendedorismo vai além de uma simples disciplina do curso. Como já foi visto, nos tópicos anteriores, o empreendedorismo pode ser aprendido por qualquer pessoa.

Em seu estudo sobre abordagem empreendedora no estimulo da construção de modelo de negócios, Dias (2016) constatou que a junção da área de formação com os conceitos da administração e prática empreendedora, podem contribuir com o surgimento de negócios inovadores. Como já mencionado nos tópicos acima, o empreendedorismo está bastante relacionado ao comportamento. E de fato, não tem como ensinar as pessoas, já na fase adulta, a agirem de acordo com as características empreendedoras.

Mas é possível sim, instigar, estimular, mostrar os benefícios ou incentivar tais atitudes, ou ainda despertar o espírito empreendedor. Para Dornelas (2001) o ensino do empreendedorismo garante a formação de melhores empresários, mas não a formação de empreendedores de sucesso. Onde são exigidos do mesmo, três competências: técnicas, habilidade de gerenciar e características pessoais. De acordo com Clark (2003 apud MOROSINI, 2006), a universidade deve ser uma instituição que está sempre se reinventando em virtude das demandas externas e internas, e chama de Universidades Empreendedoras, as instituições que o fazem.

\section{PROCEDIMENTOS METODOLÓGICOS}

A presente pesquisa foi de caráter descritivo, a partir de estudo bibliográfico, de abordagem qualitativa e quantitativa. Pois de acordo com Moresi (2003) a pesquisa bibliográfica é a realização de um estudo com base em publicações o estudo sistematizado desenvolvido com base em material publicado em livros, revistas, jornais, redes eletrônicas, isto é, material acessível ao público em geral. Fornece instrumental analítico para qualquer outro tipo de pesquisa, mas também pode esgotar-se em si mesma.

E segundo Godoy (1995, p.58), a pesquisa qualitativa "envolve a obtenção de dados descritivos sobre pessoas, lugares e processos interativos pelo contato direto do pesquisador com a situação estudada, procurando compreender os fenômenos segundo a perspectiva dos sujeitos, ou seja, dos participantes da situação em estudo". Portanto a escrita tem seu destaque na pesquisa de abordagem qualitativa tanto para obtenção de dados quanto para apresentação dos resultados (GODOY, 1995).

Ainda, de acordo com Godoy (1995), por mais que as abordagens do tipo qualitativa e quantitativa sejam caracterizadas como um esforço para descoberta de novas informações e para ampliar o conhecimento já existente, as duas pesquisas podem tomar caminhos diferentes. Portanto, nesta pesquisa, a abordagem qualitativa e quantitativa foi utilizada em momentos diferentes para obtenção dos dados e alcance dos objetivos.

A abordagem qualitativa foi usada no momento da aplicação prática do estudo, onde foram propostas atividades de interação relacionadas ao tema objetivando o instigar do empreendedorismo. Que de acordo com Godoy (1995) esta abordagem permite com que as pessoas e o ambiente sejam observados de forma holística, abrangendo o todo e não simplesmente encarados como variáveis. 
Segundo Godoy (1995, p. 58), “os pesquisadores qualitativos estão preocupados com o processo e não simplesmente com os resultados ou produto". Para tanto, esta aplicação prática foi realizada em forma de evento com a intenção de submeter os participantes a uma imersão ao tema e engajamento nas atividades interativas. Foi escolhido esse método para aplicação prática, por considerar que para instigar o empreendedorismo nas pessoas, a forma como o tema é transmitido também deve ser de caráter dinâmico.

E a abordagem quantitativa foi usada após a realização da parte qualitativa do estudo, onde será utilizada a técnica de questionário, para alcance dos objetivos desta pesquisa, e para complementar o estudo com a mensuração de dados finais. De acordo com Moresi (2003), a pesquisa de campo é a investigação realizada no local onde ocorreu ou ocorre o fenômeno pesquisado. Tal pesquisa de campo possui como instrumentos, entrevistas, aplicação de questionários teste e observação participante. No entanto, para alcance dos objetivos desta pesquisa, foram utilizados somente os instrumentos de aplicação de questionários e observação.

A coleta de dados, por meio de questionários, foi aplicada após o evento, com o intuito de identificar qual a influência do evento proposto, juntamente com a ferramenta Canvas e as atividades interativas, sobre os acadêmicos e o real alcance dos objetivos desta pesquisa. $\mathrm{O}$ questionário pós-evento conteve 8 (oito) questões fechadas e 7 (sete) questões abertas, totalizando 11 (onze) questões, aplicado a 21(vinte e um) acadêmicos.

\section{EVENTO}

Observando a dificuldade de transporte dos acadêmicos até a universidade para a participação do evento durante o dia, foi definido que a carga horária do evento seria distribuída em 4 (quatro) noites, nos dias 27 (vinte e sete), 28 (vinte e oito), 29 (vinte e nove) e 30 (trinta) de novembro de 2017 (dois mil e dezessete). O evento foi desenhado para que envolvesse os acadêmicos com a prática empreendedora. E para tal, foram utilizadas as ferramentas de palestra, atividades de interação e atividades práticas.

Foram inscritos no evento 97 (noventa e sete) acadêmicos do curso de administração da Unemat, campus de Diamantino, através da ferramenta Google Formulários, do $1^{\circ}$ (primeiro) ao $8^{\circ}$ (oitavo) semestre.

Para as palestras foram convidados, o professor Paulus Vinicius para apresentação de conceitos de empreendedorismo e sobre características do empreendedor a partir da teoria, e dois empresários, O Sr. Márcio, dono da empresa Marilac, situada na cidade de Nova Marilândia/MT, e o Sr. Jackson Ascari, gerente da franquia Cacau Show localizada na cidade de Diamantino/MT, nas quais foram enfatizadas as características empreendedoras. Os empresários compartilharam suas jornadas no empreendedorismo dando ênfase nas características que adquiriram e desenvolveram ao longo do tempo.

Uma das atividades interativas foi a atividade de autoconhecimento, que foi selecionada para aplicação no evento, em forma de pesquisa grupo focal, onde os participantes foram desafiados a refletirem sobre si mesmos, em um espaço de dez minutos, e desenvolver uma fala de no máximo 40 (quarenta) segundos para dizerem, à frente de todos, quem são.

De acordo com Pires (2016), o autoconhecimento "é o ato de buscar conhecer tudo aquilo que caracteriza o indivíduo por si próprio". Ou seja, autoconhecimento consiste em conhecer quais são suas próprias qualidade, limitações, imperfeições, sentimentos, potencialidades e valores. Pires (2016) traz que, o indivíduo, quando passar a ter consciência de quem realmente é, começa a desenvolver suas potencialidades, reconhecendo e buscando corrigir seus próprios erros. E além de aceitar e valorizar a si mesmo, aceita e valoriza ao outro 
com maior facilidade. E com isso, acaba, consequentemente, transformando o mundo que o rodeia.

Como atividade interativa foi utilizada também a simulação de negociação. Onde os participantes, divididos em quatro grupos, e com auxílio de textos, desenvolveram estratégias de compra e venda, e simularam uma negociação entre empresas, durante trinta minutos. Foi utilizada também a dinâmica do "Desafio", com a qual os acadêmicos foram estimulados a enfrentarem os desafios que surgirem na vida pessoal e profissional. E como atividade prática, foi proposto o desenvolvimento de modelos de negócios com o quadro Canvas. $\mathrm{O}$ desenvolvimento de todas as atividades citadas neste foram observadas em forma de pesquisa grupo focal.

\section{ANÁLISE E APRESENTAÇÃO DOS DADOS}

Para a apresentação dos resultados, considere: $21=100 \%$.

\section{a) Dados Gerais}

A maior parte dos acadêmicos, $76 \%$ (setenta e seis por cento), possuem idade entre 20 (vinte) e 25 (vinte e cinco) anos. Dos 21 (vinte e um) participantes desta pesquisa, apenas 6 (seis) eram do sexo masculino. Durante o evento foi possível perceber envolvimento maior da turma do sétimo semestre do curso de administração. No último dia, como exemplo, compareceram 22 (vinte e dois) acadêmicos dessa turma. 13 (treze) acadêmicos da turma do $5^{\circ}$ (quinto semestre), 4 (quatro) da turma do $6^{\circ}$ semestre e apenas 2 (dois) acadêmicos da turma do $2^{\circ}$ (segundo) semestre. Percebendo assim, um maior engajamento ao tema de turmas mais avançadas no curso de Administração.

O público do curso está divido entre, $52 \%$ (cinquenta e dois por cento) acadêmicos que residem na cidade de diamantino, onde está localizada a universidade objeto desta pesquisa, e $48 \%$ (quarenta e oito por cento) reside nas cidades próximas.

\section{b) $O$ evento alcançou as expectativas dos participantes.}

A divulgação do evento no curso de administração através dos professores criou certa expectativa nos acadêmicos, por se tratar de um evento de empreendedorismo, onde o próprio tema é referência de algo diferente e inovador, e também por conta da ferramenta Canvas que ainda não conheciam. Com os resultados da pesquisa foi possível verificar que o evento alcançou tais expectativas. No gráfico a seguir, como exemplo, tanto os palestrantes quanto a oportunidade para fazer networking e o atendimento prestado durante o evento pelos facilitadores, atingiram as expectativas de até $60 \%$ (sessenta por cento) dos participantes. Em relação ao item, número de participantes, apenas $24 \%$ (vinte e quatro por cento) se sentiram satisfeitos, enquanto os demais acreditam que o evento poderia envolver um número maior de pessoas. Vide Gráfico 1. 
Gráfico 1: Pesquisa Pós-evento - Áreas que alcançaram as expectativas

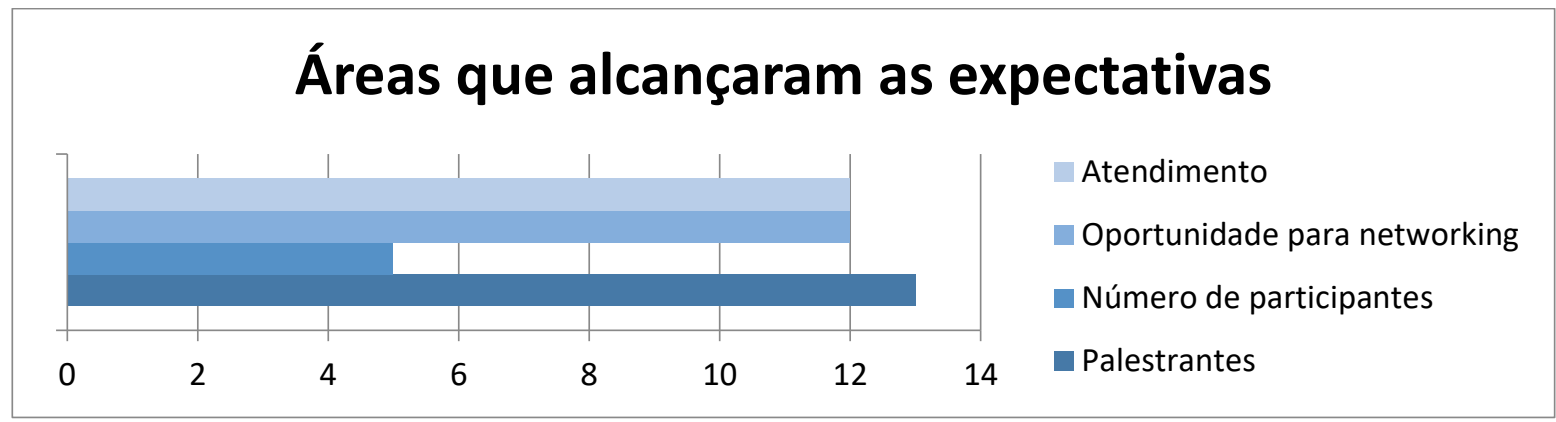

Fonte: A pesquisa

c) houve falta de participação de alguns acadêmicos.

$\mathrm{O}$ que mais incomodou os acadêmicos foi o fato de que alguns integrantes do grupo não se mostraram engajados com as atividades, o pode também ter atrapalhado o desenvolvimento daqueles que se mostraram realmente interessados no assunto que estava sendo discutido. Vide Gráfico 2.

Gráfico 2: Pesquisa Pós-evento - O que menos gostaram no evento / Indicadores

\section{O que menos gostou no evento?}

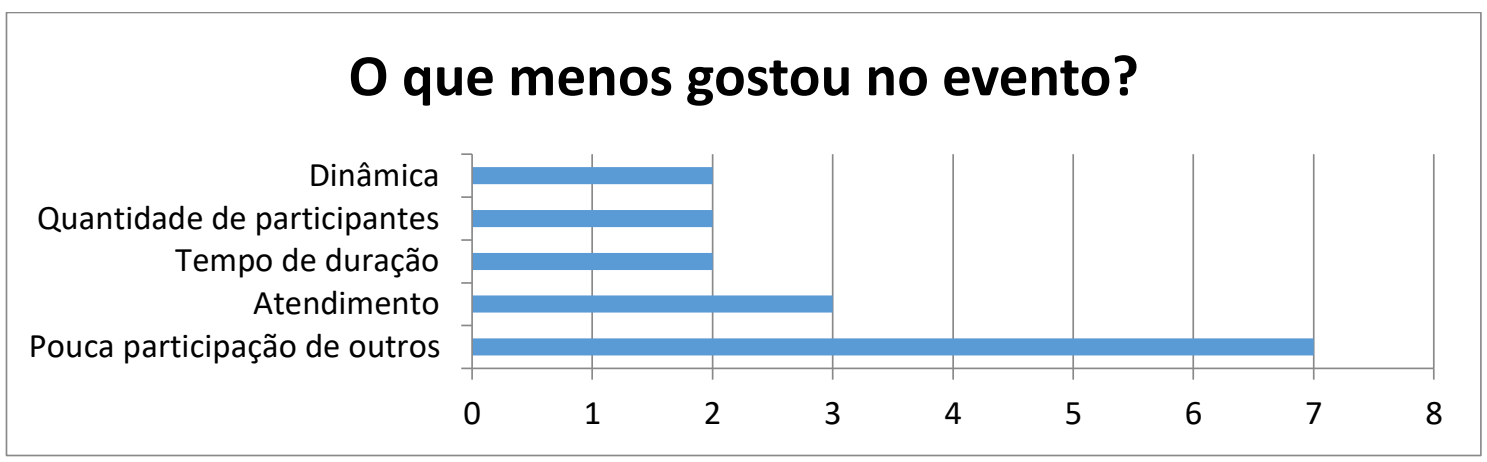

Fonte: A pesquisa.

d) dos 21 participantes desta pesquisa, apenas 1 conhecia a ferramenta.

$100 \%$ (cem por cento) dos participantes ainda não haviam participado de um evento com o tema empreendedorismo até o momento, ao menos não com a interatividade que o evento "Jornada Empreendedora de Administração" propôs. 100\% (cem por cento) dos acadêmicos voltariam a participar de mais eventos com essa temática, até mesmo de uma nova edição deste mesmo evento, e também indicariam a participação deste evento para outras pessoas. Quanto ao conhecimento da ferramenta Canvas, 96\% (noventa e seis por cento) dos participantes revelaram não terem conhecimento sobre esta ferramenta antes do evento. suas vidas.

e) os participantes acreditam precisar usar a ferramenta em outros momentos de

É interessante mencionar que mesmo sem apresentar o Canvas como uma ferramenta útil também para desenvolver assuntos pessoais e não só profissionais, os participantes conseguiram visualizar sozinhos esse valor agregado à ferramenta. 
As respostas ficaram divididas entre os indicadores; vida pessoal, onde os participantes alegaram poderem usar a ferramenta para organizar e planejar a vida pessoal. Como exemplo, temos a resposta do questionário 18 , que diz que a ferramenta poderá ser aplicada na própria casa. E abrir o próprio negócio, onde a ferramenta os auxiliará a se planejarem melhor e a se atentarem a pontos importantes de um negócio quando forem empreender. Vide Gráfico 3.

Gráfico 3: Pesquisa Pós-evento - Aplicabilidade da ferramenta Canvas / Indicadores

\section{Aplicação da ferramenta Canvas}

Vida pessoa

Para abrir o próprio negócio

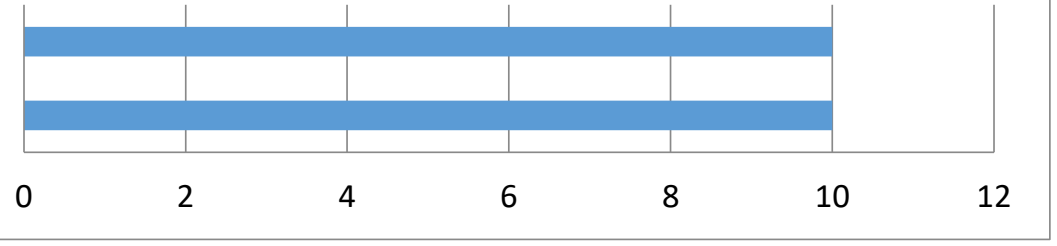

Fonte: A pesquisa

f) as atividades contribuíram com o desenvolvimento de características.

Com as respostas conseguidas através da questão 13 (treze) foi possível identificar dois indicadores. O primeiro, características, representa o grupo de participantes que afirmam que as atividades interativas propostas contribuíram com o desenvolvimento de características pessoais. E o indicador conhecimento, representa o quanto tais atividades contribuíram para agregar ao conhecimento dos acadêmicos, em relato dos mesmos. Vide Gráfico 4.

Gráfico 4: Pesquisa Pós-evento - Contribuição das atividades à formação pessoal

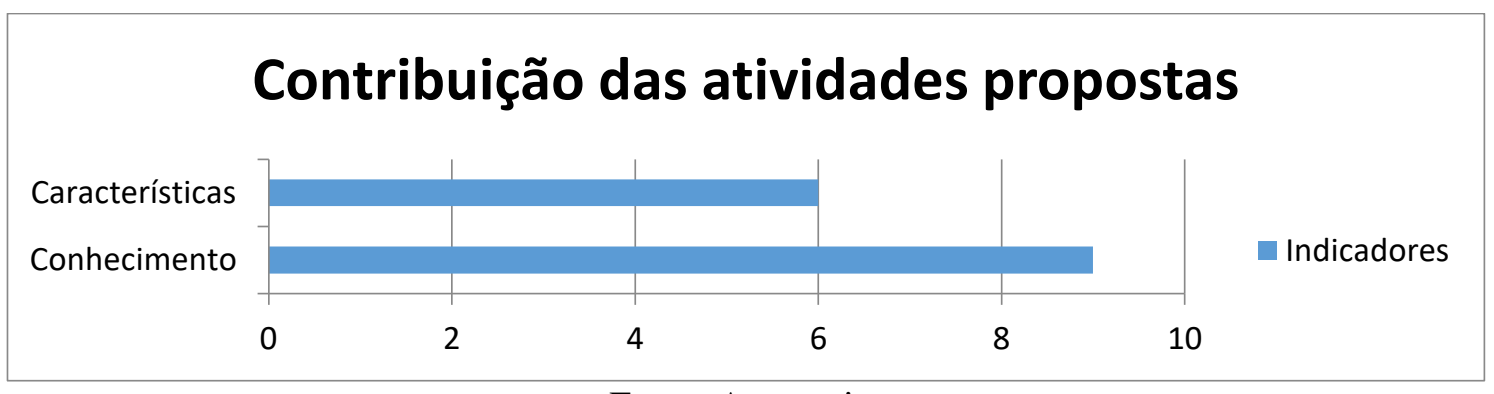

Fonte: A pesquisa

g) a ferramenta Canvas contribuiu com o desenvolvimento profissional.

Os acadêmicos foram questionados sobre a influência da ferramenta Canvas no desenvolvimento profissional. Onde 62\% (sessenta e dois por cento) dos participantes responderam que a ferramenta contribuiu com o desenvolvimento profissional. Ainda assim, foi possível criar dois indicadores a partir dos dados coletados; planejamento de negócios, que segundo os participantes, a ferramenta será bastante útil quando forem abrir negócios próprios. $\mathrm{E}$, diferencial enquanto profissional administrador. Os mesmos afirmam que conhecer a aplicabilidade de uma ferramenta importante como o Canvas, os fará destacar no mercado de trabalho. Vide Gráfico 5. 
Gráfico 5: Pesquisa Pós-evento - Contribuição da ferramenta Canvas à formação profissional

\section{Contribuição da ferramenta Canvas}

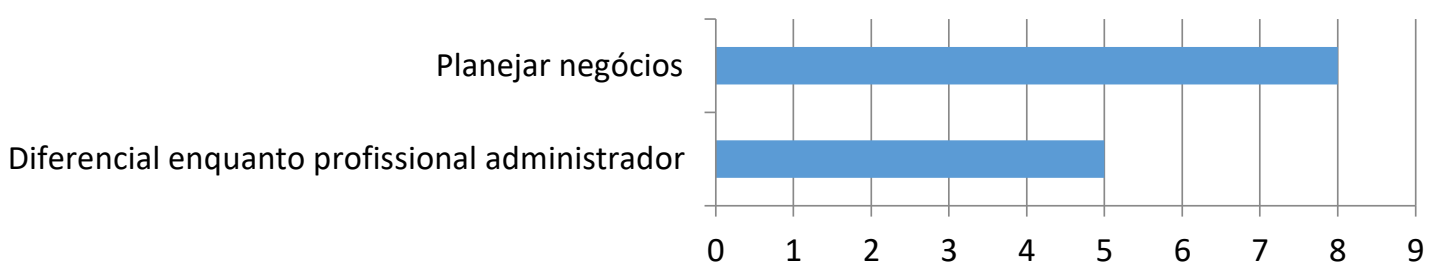

Fonte: A pesquisa

\section{DISCUSSÃO DOS RESULTADOS}

Com base nos dados coletados, qualitativos, qualitativos e bibliográficos, é possível apontar algumas considerações.

\section{propostas.}

A) os acadêmicos foram instigados ao empreendedorismo a partir das atividades

De acordo com os dados coletados mais de $75 \%$ (setenta e cinco por cento) dos acadêmicos foram instigados ao empreendedorismo. Como exemplo tem-se o questionário 14 (quatorze) em resposta a uma das questões realizadas na pesquisa pós-evento, sobre o quão as atividades teriam influenciado sua formação pessoal e/ou profissional, onde o mesmo diz que as atividades influenciaram de um jeito que fez com que todos pudessem refletir sobre a importância de ser um empreendedor e de se ter organização para colocar as ideias em prática. Outro exemplo de alcance do objetivo de instigar o empreendedorismo é o questionário 15 (quinze), que conta, também em resposta a pesquisa pós-evento, que as atividades deram um incentivo a mais para buscar novos conhecimentos.

B) foi desenvolvida a percepção dos acadêmicos em relação ao empreendedorismo e a criação de negócios inovadores.

Em relação aos negócios, foi verificado que os participantes conseguiram desenvolver negócios com diferenciais de mercado. E em relação ao empreendedorismo, boa parte dos acadêmicos se mostrarem bastante interessados e comprometidos com o tema, apesar de revelarem insatisfeitos com o baixo engajamento de outros participantes, como mostra o resultado "c". Ou seja, os participantes ficaram bem divididos entre aqueles que possuem características intraempreendedores e aqueles que não possuem tais características de forma expressiva.

C) a ferramenta Canvas contribuiu com o desenvolvimento de características empreendedoras aos acadêmicos.

No resultado "e" da pesquisa pós-evento, os mesmos apresentam a necessidade de uso da ferramenta Canvas para elaborar planejamento, tanto na vida pessoal quanto para abrir um negócio próprio. Como descreve o questionário 1 (um) ao dizer que "aplicaria em meu futuro Negócio antes de abrir para saber e ter mais conhecimento do que irei atingir com meu negócio". Ou seja, os acadêmicos poderão usar a ferramenta para calcular e planejar tomadas de decisões em diversos momentos de suas vidas.

$\mathrm{O}$ que coincide também com os resultados da pesquisa pré-evento, onde revela que mais de $60 \%$ (sessenta por cento) dos acadêmicos pretendem abrir o próprio negócio nos 
próximos três anos. Não só esta característica, como também a iniciativa que foi percebida durante as dinâmicas, o comprometimento e o aprendizado com os próprios erros.

\section{CONSIDERAÇÕES FINAIS}

\section{"Novos tempos exigem novas posturas".} (SEBRAE NACIONAL, 2017).

Está muito claro que o tempo em que vivemos hoje está pedindo por mudanças e novas posturas. Não só por parte das instituições, como foi apresentado neste, mas também requer que os indivíduos adotem uma posição diferente em relação ao comportamento e atitudes. $\mathrm{O}$ mercado está exigindo isso. São gradativas às vezes em que vemos empresas buscando profissionais no mercado já com características empreendedoras, ou em vermos mais e mais pessoas investindo em negócios próprios.

A intenção inicial dessa pesquisa foi criar meios para que os acadêmicos da universidade, parte do objeto de estudo, fossem encorajados a tirar suas ideias do papel. Não precisa que nem ninguém diga aos acadêmicos que ser empreendedor é a tendência, ou que vão ter mais chances de sucesso se desenvolverem características empreendedoras. Os mesmos já sabem disso. O que falta é o "empurrãozinho". Pode ser que empreendedores natos não precisem desse incentivo, pois tendem a ter motivação própria. Mas, olhe a sua volta. Quantos dos que vê, você acredita ser um empreendedor nato? São raros. E a preocupação é com os demais.

Acredita-se que o empreendedorismo pode ser ensinado e as características empreendedora, estimuladas. Então como apresentar o mercado exigente de hoje para o acadêmico já o inserindo nessa realidade? $O$ objetivo deste trabalho foi instigar o empreendedorismo aos acadêmicos do curso de administração, a partir de um evento. Mas sem enfatizar a teoria como normalmente ocorre no ensino das disciplinas do curso, e sim, enfatizando a prática empreendedora.

Primeiro, buscou-se na teoria entender melhor conceitos de empreendedorismo, o que é ser empreendedor e sobre o desenvolvimento de ações empreendedoras dentro das universidades. A partir disso foi desenhado um evento, usando como referência o evento "Desafio Universitário Empreendedor - SEBRAE", que proporcionasse uma imersão ao empreendedorismo com as adaptações necessárias para a realidade do campus, como exemplo, a carga horária. Que foi divida em quatro noites ao invés de ser aplicada durante o dia. Justamente pelo fato de o público da universidade ser $50 \%$ (cinquenta por cento) oriundo das cidades vizinhas, como pôde ser constatado nos resultados das pesquisas pré e pós-evento. Criando assim, dificuldades maiores de locomoção até o local durante o dia.

Por fim, fica registrado aqui, o quão gratificante foi ler os comentários dos participantes da pesquisa pós-evento. Com certeza os resultados desta pesquisa como um todo superou as expectativas da autora, tanto que, foi emocionante perceber que de algum jeito sua pesquisa contribuiu com o conhecimento de outras pessoas. Houve um propósito desde o início, e com muito trabalho duro e muita pesquisa, o evento alcançou seus objetivos de instigar de fato o empreendedorismo aos acadêmicos. E que o evento sirva como modelo para próximas edições. Pois acredita-se que a oferta de experiências relacionadas ao empreendedorismo na universidade deve ser contínua.

Com o estimulo a características empreendedoras, espera-se que o ambiente na universidade se transforme com acadêmicos mais ativos e engajados no processo de 
aprendizagem dentro da instituição. Acredita-se que os mesmos consigam transportar essa experiência empreendedora para a vida pessoal e profissional também. Contudo, é a sociedade que tem a ganhar. Pois esse incentivo pode permitir com que a universidade entregue a comunidade ainda mais valor, quando a mesma contribui para o desenvolvimento dos futuros profissionais com atitudes empreendedoras, ela está também contribuindo para desenvolvimento econômico e social da comunidade em que está inserida.

Sobre as limitações da pesquisa, ela foi desenvolvida para atender a uma demanda existente no curso de Administração do campus, no entanto, de acordo com a valorização do networking pelos acadêmicos, como observado na pesquisa pós-evento, percebeu-se que o networking ficou limitado somente aos conhecimentos gerados na área, sem explorar a visão crítica de outras áreas de estudos, como por exemplo, dos cursos de direito, educação física e enfermagem, que são as outras três graduações disponibilizadas no campus de Diamantino-MT.

Para as futuras pesquisas sobre o tema, caso haja uma segunda edição do evento, ou caso o leitor queira aplica-lo em seu ambiente de trabalho ou de estudo, considere algumas adequações. Como exemplo, o fato de o evento ter começado após às $20 \mathrm{~h} 00 \mathrm{minh}$ fez com que os acadêmicos considerassem a carga horária muito extensa. Sugere-se então que, na aplicação do evento, a organização se atente em cumprir com o cronograma e em ofertar uma carga horária em que o público se sinta confortável.

E para que haja um envolvimento ainda maior de todos os participantes, recomendase que o evento seja aberto somente para aqueles que quiserem realmente participar, ao invés de convidar toda uma turma como ocorreu neste. Como exemplo, tem-se o fato de que apenas dois acadêmicos do $2^{\circ}$ (segundo) semestre participaram todos os dias do evento, por interesse genuíno ao tema e à ferramenta.

\section{REFERÊNCIAS}

CHIAVENATO, Idalberto. Empreendedorismo: dando asas ao espírito empreendedor. 4. ed. São Paulo: Manole, 2012.

COSTA, Alessandra Mello; BARROS, Denise Franca; MARTINS, Paulo Emílio Matos. A alavanca que move o mundo: o discurso da mídia de negócios sobre o capitalismo empreendedor. Cadernos EBAPE. BR, v. 10, n. 2, artigo 6. Rio de Janeiro: FVG, 2012. p.357375. Disponível em:< http://www.scielo.br/pdf/cebape/v10n2/v10n2a07>. Acesso em: 24 set. 2017.

DIAS, K. N. SILVA, V. B. TOLFO, C. Relato de experiência: criação de negócios inovadores de base tecnológica a partir da disciplina de administração e empreendedorismo. Revista da Jornada de Pós-Graduação e Pesquisa. 13 Jornada. Congrega. Urcamp, 2016. Disponível em: <http://trabalhos.congrega.urcamp.edu.br/index.php/jpgp/article/view/329/1050>. Acesso em: 8 set. 2017.

DOLABELA, Fernando. O Segredo de Luísa. São Paulo: Cultura, 1999.

DORNELAS, José Carlos Assis. Empreendedorismo: transformando ideias em negócios. Rio de Janeiro: Elsevier, 2001.

3. ed. Rio de Janeiro: Elsevier, 2008. Disponível em: $<$ https://books.google.com.br/books?hl=ptBR\&lr=\&id=oKlayz7rBVIC\&oi=fnd\&pg=PA1\&d 
$\mathrm{q}=$ dornelas+2008\&ots=PJvKNjZ6wK\&sig=ZioksPphH_9JYrFKaQHNIXNsA00\&redir_esc= $\mathrm{y} \# \mathrm{v}=$ onepage $\& \mathrm{q}=$ dornelas\%202008\&f=false>. Acesso em 18 de set. 2017.

FILION, Louis Jacques. Entendendo os Intraempreendedores como Visionistas. Revista de Negócios, Blumenau, v. 9, n. 2, p. 65-80, abril/junho 2004.

GODOY, Arlida Schmidt. Introdução à Pesquisa Qualitativa e suas Possibilidades. São Paulo: Revista de Administração de Empresas, 1995. Disponível em:

http://www.scielo.br/pdf/rae/v35n2/a08v35n2.pdf >. Acesso em: 30 jul. 2017.

HENRIQUE, Daniel Christian. CUNHA, Sieglinde Kindl da. Práticas didático-pedagógicas no ensino de empreendedorismo em cursos de graduação e pós-graduação nacionais e internacionais. RAM, Rev. Adm. Mackenzie [online]. 2008, vol.9, n.5, pp.112-136. ISSN 1678-6971. Disponível em: < http://dx.doi.org/10.1590/S1678-69712008000500006 >. Acesso em: 28 set. 2017.

MAXIMIANO, Antonio Cesar Amaru. Empreendedorismo. São Paulo: Pearson Prentice Hall, 2012.

MIGLIOLI, Afrânio Maia. TRAINA, Antônio Fernando. TACHIBANA, Wilson Kendy. Empreendedorismo: a importância de se planejar o negócio antes de torná-lo realidade. Anais...XIII SIMPEP, Bauru, 2006.

MOROSINI, Marilia. Organizadora. A universidade no Brasil: concepções e modelos. Brasília: Instituto Nacional de Estudos e Pesquisas Educacionais Anísio Teixeira, 2006. Disponível em: < file:///C:/Users/'maiza/SkyDrive/Documentos/TCC/Artigo\%20\%20universidade\%20do\%20Brasil.pdf >. Acesso em 3 ago. 2017.

NASSIF, Vânia Maria Jorge. ANDREASSI, Tales. SIMÕES, Fabíola. Competências Empreendedoras: há diferenças entre empreendedores e intraempreendedores? v. 8, n. 3, São Paulo: Revista de Administração e Inovação, 2011. p.33-54.

SALVI, E. J. et al. A influência da disciplina de empreendedorismo no comportamento e nas atitudes empreendedoras: percepção dos alunos que frequentaram a disciplina no Centro Universitário UNIVATES. Anais...VII Convibra - Congresso Virtual Brasileiro de Administração, 2010.

SEBRAE NACIONAL. Disponível em: < https://www.sebrae.com.br/sites/PortalSebrae>. Acesso em 18 set. 2017

SEBRAE. Sobrevivência das Empresas no Brasil. Marco Aurélio Bedê (Coord.) - Brasília: SEBRAE, $2016 . \quad$ Disponível em: <https://www.sebrae.com.br/Sebrae/Portal\%20Sebrae/Anexos/sobrevivencia-das-empresasno-brasil-102016.pdf>. Acesso em 17 set. 2017.

SILVA, Allan Ferreira da. Et al. Análise Bibliométrica Sobre Intraempreendedorismo e Seus Direcionamentos. Revista FOCO: Periódico dos Programas de Graduação e Pós-Graduação em Administração e Recursos Humanos. V.10, n³, p. 46- 66, ago./dez. 2017. Disponível em: 
<https://www.researchgate.net/profile/Kamille_Ramos_Torres/publication/321508765_Versa o_completa_v10_n3_ago_dez_2017/links/5a94516e45851535bcdab06b/Versao-completav10-n3-ago-dez-2017.pdf\#page=48 >. Acesso em: 16 set. 2018.

ZAMPIER, Marcia Aparecida. Et al. Intraempreendedorismo Feminino e Desenvolvimento de Competências Empreendedoras: Um Estudo de Caso com Professoras de Programas de Mestrado e Doutorado em Administração de Curitiba-PR. Curitiba: Revista Economia \& Gestão - v. 11, n. 25, jan./abril. 2011. 